\title{
Alveolar Pressure Swings during High Frequency Ventilation in Rabbits
}

\author{
IVAN D. FRANTZ III AND RICHARD H. CLOSE \\ Department of Pediatrics, Division of Newborn Medicine, Harvard Medical School and The Children's Hospital, \\ Boston, Massachusetts, 02115
}

\begin{abstract}
In order to understand the pressures and volumes delivered during ventilation with the Emerson flow-interrupting high frequency ventilator, we have measured dynamic and mean pressures at the airway opening, trachea, and alveoli as well as delivered volumes in vivo in closed-chest adult rabbits ventilated at rates of $2-37.5 \mathrm{~Hz}$. To measure alveolar pressure we opened the chest, glued an alveolar capsule to the visceral pleural surface, punctured the pleura and lung surface through the capsule, inserted a pressure transducer into the capsule and closed the chest. We measured delivered volume with a pressure plethysmograph. Alveolar pressure swings fell with increasing frequency, as did delivered volume. Alveolar pressure swings were always lower than those at the airway opening or in the trachea. Removal of the rib cage resulted in a decrease in alveolar pressure swings although muscle paralysis had little effect. Mean pressures were equal at the airway opening, trachea, and alveoli at all frequencies. These results suggest that using the high frequency ventilator tested, to minimize alveolar barotrauma one should choose the highest frequency where gas exchange is adequate. (Pediatr Res 19: 162-166, 1985)
\end{abstract}

\section{Abbreviations}

HFV, high frequency-low tidal volume ventilation

HFV is currently under investigation as a new technique for treatment of adults and infants with respiratory failure $(2,3,6$, $8,10,15)$. Its major advantage is the potential for adequate gas exchange with lower dynamic pressures within the airways. While there is evidence that dynamic pressure in the trachea may be lower during HFV than during conventional ventilation (6), data from our laboratory demonstrate that under conditions of low oscillatory flow and pressure amplitudes, alveolar pressure swings may exceed those at the airway opening near the resonant frequency of the respiratory system $(1,7)$. Although these data provide important physiologic information, they do not have direct clinical relevance since the experiments were carried out using dynamic pressures at the airway opening which were very much lower than those used for HFV. Furthermore, excised lungs were studied, eliminating effects of the chest wall. The objectives of this study were to measure dynamic pressure within the alveoli in vivo in response to pressure oscillations generated

Received July 23, 1984; accepted September 14, 1984.

Address for correspondence Ivan D. Frantz III, M.D., The Children's Hospital, 300 Longwood Avenue, Boston, MA 02115.

Supported in part by Pediatric Pulmonary SCOR HL27372 from the National Heart Lung and Blood Institute. at the airway opening with a clinically used high frequency ventilator, investigate the effect of the chest wall on alveolar pressure, and quantify tidal volumes delivered. The pressure oscillations applied at the airway opening differ substantially in both magnitude and waveform from those used in the previous studies $(1,7)$.

\section{METHODS}

Measurements were made in 11 New Zealand White rabbits ranging in weight from $3-5 \mathrm{~kg}$. The animals were anesthetized with $30 \mathrm{mg} / \mathrm{kg}$ sodium pentobarbital intravenously and were placed on a warming pad. A tracheostomy was performed $1 \mathrm{~cm}$ below the larynx, and a $3.5 \mathrm{~mm}$ internal diameter endotracheal tube $10 \mathrm{~cm}$ long was placed $3 \mathrm{~cm}$ into the trachea and tied securely. Tracheal pressure was measured with a $0.75 \mathrm{~mm}$ inside diameter side-hole catheter $9 \mathrm{~cm}$ long, with the side hole $1 \mathrm{~cm}$ beyond the endotracheal tube tip. This catheter was inserted through the tracheostomy incision alongside the endotracheal tube.

Alveolar pressure was measured through capsules placed on the pleural surface in six animals in the following manner. The animal was placed in the left lateral position and an incision made in the right 6th intercostal space at the posterior axillary line. After dissecting through the subcutaneous tissue and intercostal muscle, the ribs were spread and a plastic capsule was attached to the visceral pleura of the right lower lobe using cyanoacrylate glue (Fig. 1). The lungs were maintained at $10 \mathrm{~cm}$ $\mathrm{H}_{2} \mathrm{O}$ distending pressure while the capsule was attached. Subsequently the ribs were sutured together and the subcutaneous tissue closed. Two or three punctures of the pleural surface were made with an 18-gauge needle through the capsule to a depth of 2-3 $\mathrm{mm}$, and a pressure transducer was inserted into the capsule.

Pressure at the airway opening was measured through a sidehole in the $2 \mathrm{~cm}$ diameter connector at the junction of the endotracheal tube and ventilator circuit. All pressures were measured using piezoresistive pressure transducers (Endevco model 8510). The frequency response of the transducers is flat to 45,000 $\mathrm{Hz}$. The frequency response of the transducer and catheter or alveolar capsule combinations was tested and was flat to within $\pm 0.5 \%$ in amplitude and $\pm 5^{\circ}$ in phase in the range studied (57, 9).

Although it is not possible to verify alveolar pressure measurements directly, we ruled out two possible sources of artifact. First, pressure in the capsule may not accurately reflect pressure in the alveoli beneath it because of the time constant of the capsule system. We varied the time constant of the system widely by placing cellophane tape with punctures over the capsule surface to simulate the resistance of pleural punctures and by adding $1-20 \mathrm{~cm}$ lengths of tubing (varying volume from $0.23-$ $2.1 \mathrm{~cm}^{3}$ ) between the capsule and transducer to vary gas compli- 
placed on a pressure limited ventilator (Baby Bird) at a rate of $36 \mathrm{~min}^{-1}$ with a peak pressure at the airway opening of $20 \mathrm{~cm}$ $\mathrm{H}_{2} \mathrm{O}$ and a constant distending pressure of $5 \mathrm{~cm} \mathrm{H} \mathrm{H}_{2} \mathrm{O}$. Pressures at the airway opening, in the trachea, and in the alveolar capsule were observed to be within $\pm 1 \mathrm{~cm} \mathrm{H}_{2} \mathrm{O}$ of each other and the animals were switched to the high frequency ventilator with an $\mathrm{FIO}_{2}$ of 0.21 . After inflation to $30 \mathrm{~cm} \mathrm{H}_{2} \mathrm{O}$, mean airway pressure was adjusted to $10 \mathrm{~cm} \mathrm{H}_{2} \mathrm{O}$ and pressure swings were recorded at $2,5,10,15,20,25,30$, and $37.5 \mathrm{~Hz}$. These measurements were repeated after administration of $0.1 \mathrm{mg} / \mathrm{kg}$ pancuronium for muscle relaxation. The animals were then sacrificed and the location and integrity of the alveolar pressure capsule were verified. In three animals, the rib cage was excised, and the measurements repeated in the absence of the chest wall. In an additional three animals, tidal volumes were measured with the chest both closed and open.

Statistical analysis was carried out with a multifactor analysis of variance using the General Linear Models Procedure from the SAS Institute Statistical Package (13).

\section{RESULTS}

All of the animals were alive at the end of the period of closedchest ventilation. The capsules were securely attached to the lung surface and without leaks when the chests were opened at the conclusion of the experiment. Pressure swings were equal at the airway opening, trachea, and alveoli during conventional ventilation at the start of each experimental run, thus establishing that the three sites were in continuity in a situation of low flows near the static limit.

The data are discussed in terms of the fundamental frequency although it can be noted from a tracing of pressure versus time (Fig. 3) that higher harmonics were present. Tidal volume diminished as frequency increased (Fig. 4) and oscillatory flow $\left(\pi \mathrm{fV}_{\mathrm{I}}\right)$ showed a slight increase, although it was relatively constant over the range of 10-25 Hz (Fig. 5).

The peak-to-peak pressure swings at the airway opening, in the trachea, and in alveoli at the right lower lobe surface are plotted against frequency for the anesthetized, paralyzed, closedchest animals (Fig. 6). Pressure swings at the airway opening were relatively constant with increasing frequency, while those in the trachea and alveoli tended to fall. A major drop in dynamic pressure occurred across the endotracheal tube and a smaller drop was noted between the trachea and alveoli.

Comparison of alveolar pressure swings in the anesthetized, anesthetized, $c$

that pressure $\mathrm{s}$ those in the clc
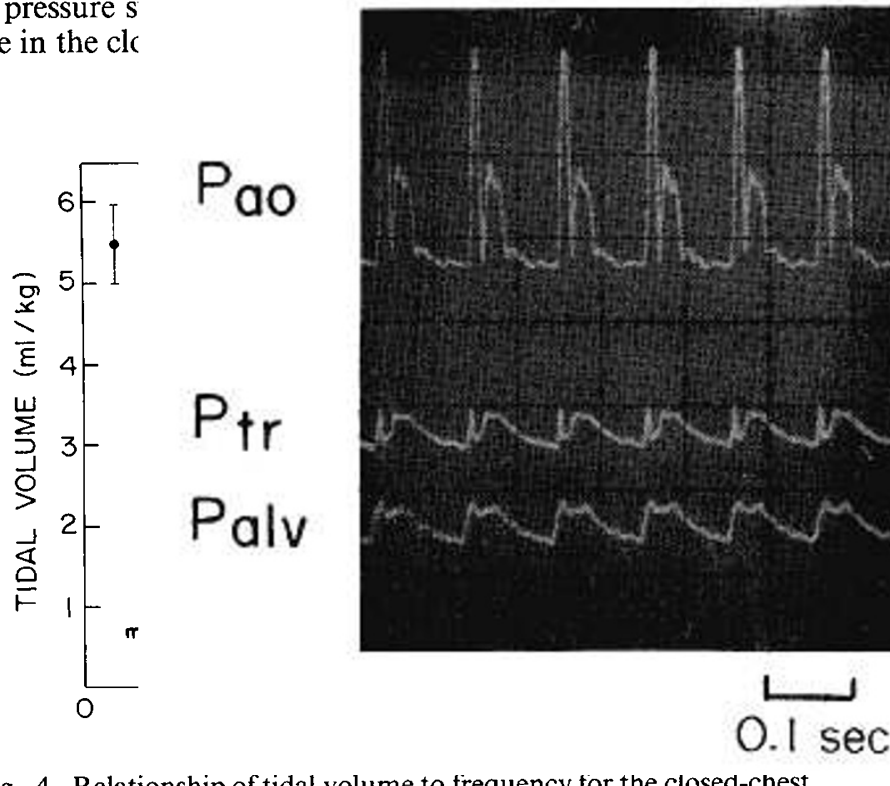

Fig. 5. Relationship of oscillatory flow at the chest wall to frequency
for the closed-chest anesthetized, paralyzed animals. Values are mean \pm $\mathrm{SD}$ for five animals.

Fig. 4. Relationship of tidal volume to frequency for the closed-chest, anesthetized, paralyzed animals. Values in $\mathrm{ml} / \mathrm{kg}$ body weight are mean $\pm \mathrm{SD}$ for five animals.

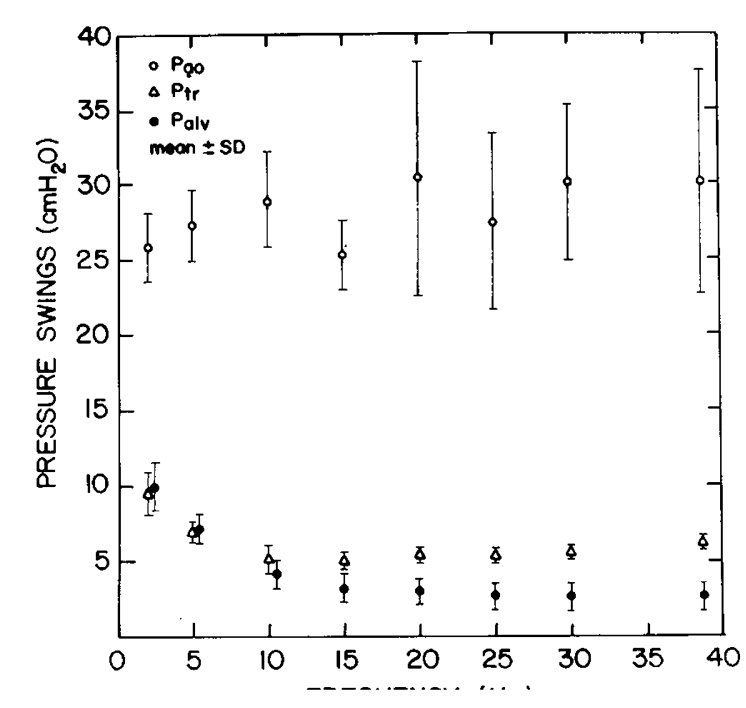

Fig. 5. Relationship of oscillatory flow at the chest wall to frequency
for the closed-chest anesthetized, paralyzed animals. Values are mean \pm

( $\mathrm{P}_{a o}$, open circles), ircles) plotted versus
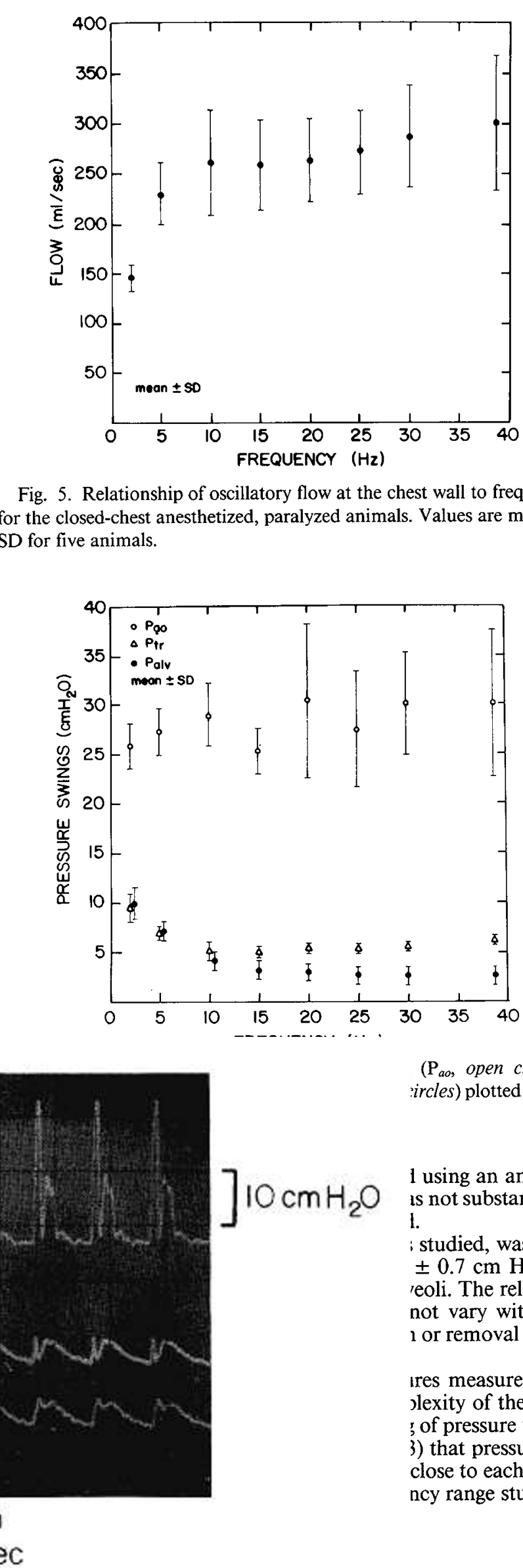

1 using an analysis is not substantially ; studied, was 11.0 $\pm 0.7 \mathrm{~cm} \mathrm{H}_{2} \mathrm{O}$ in ,eoli. The relation1 or removal of the

Ires measured was Jlexity of the presy of pressure versus 3) that pressures at close to each other ncy range studied. sure directly in vivo during high frequency ventilation. We found that during ventilation with the Emerson flow interrupter dynot vary with fre-

we nave aeveioped a tecnmyue ior estundting alveolar pres- 
ance. Pressures in a test chamber measured through the capsule system were compared to those measured with a reference transducer, and varied by less than $0.5 \%$.

Second, to test for mechanical influences of the capsule system on pressures measured after attachment to the lung, mass was added to the capsule, and the capsule was manually tilted up to $45^{\circ}$ from vertical in each direction and pressures compared to those measured without added mass or tilting. No effect of either adding mass or tilting was discerned. Signals were amplified using Tektronix AM502 amplifiers and recorded on magnetic tape. Data were analyzed by playing the tapes back onto an oscilloscope screen and photographing the screen. Peak-to-peak pressure swings were then calculated from the photographs. Mean pressures were determined by low-pass-filtering the signals below $0.2 \mathrm{~Hz}$.

Delivered tidal volumes were measured in five additional animals. Alveolar pressure capsules were not applied in these animals. The animals were placed in a 30 -liter plexiglas pressure plethysmograph with their tracheostomy tubes exteriorized. An Endevco 8510 pressure transducer was used to measure box pressure. The frequency response of the plethysmograph was

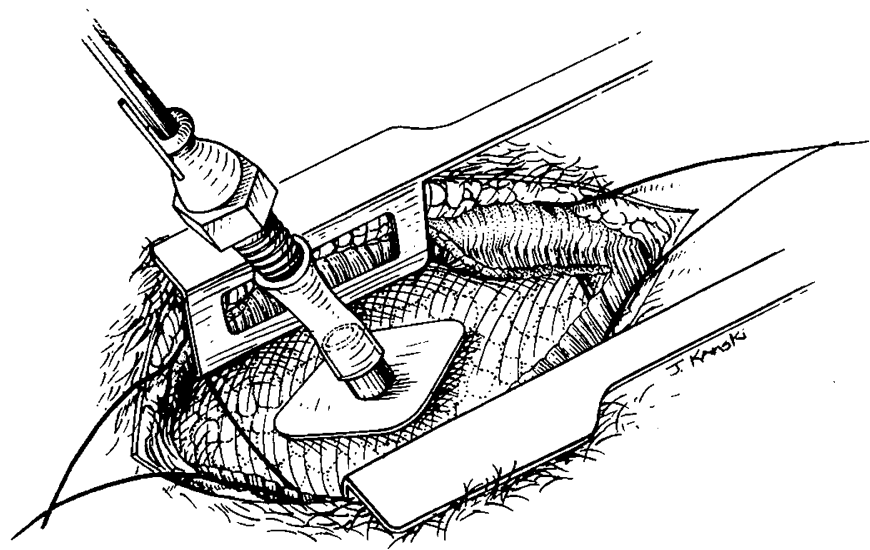

Fig. 1. Diagram of alveolar pressure adapter applied to the visceral pleural surface of the lung. After removal of the retractor, the ribs were sutured tightly around the adapter and the soft tissue closed. The outside diameter of the adapter was $3.5 \mathrm{~mm}$, and it was connected to the transducer by a $1.5 \mathrm{~cm}$ length of tubing. tested by breaking balloons in the box and observing the time course of the pressure response. The $95 \%$ response time was such that frequency response was adequate to much greater than 40 $\mathrm{Hz}$. Box temperature remained constant at $25.0 \pm 1^{\circ} \mathrm{C}$. Frequency sweeps were made from high to low or low to high in alternate experiments with similar results.

The high frequency ventilator used was the Emerson rotating ball valve device. The circuit and settings were the same as we have previously described $(5,6)$ (Fig. 2). A bias flow of 35 liters/ min from a high impedance source was conducted through the ball valve past the animal's airway using standard $2 \mathrm{~cm}$ diameter respiratory tubing. The downstream limb of the circuit (past the airway adapter) was a $3 \mathrm{~m}$ length of the same tubing. Mean pressure was controlled at $10 \mathrm{~cm} \mathrm{H}_{2} \mathrm{O}$ using a variable resistance at the distal end of the downstream limb.

After the surgical preparation was complete, the animals were

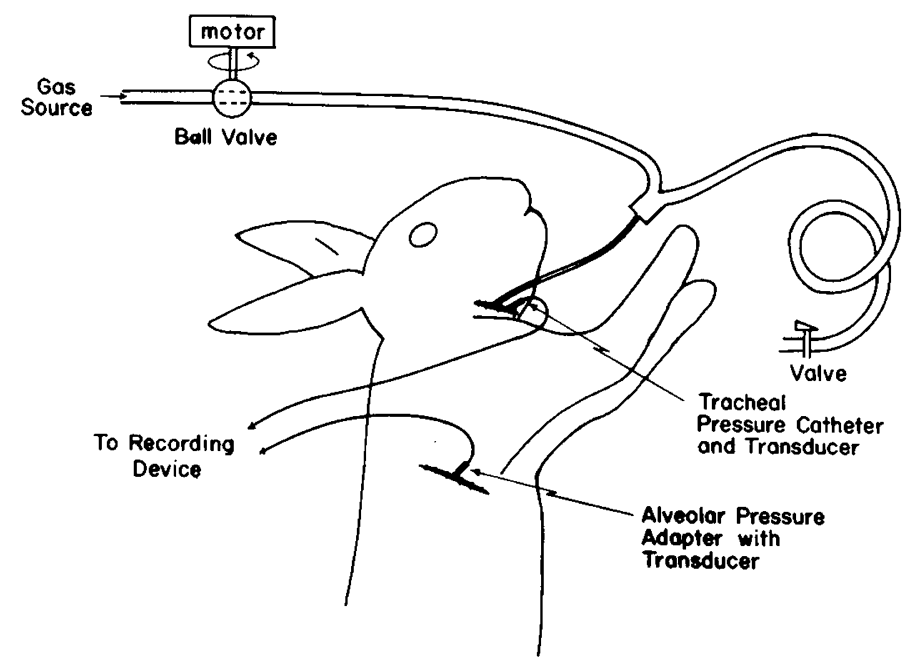

Fig. 2. Schematic diagram of apparatus. A bias flow of gas was passed through the rotating ball valve past the animal's airway. The tubing was $2.5 \mathrm{~cm}$ in diameter and the portion downstream from the subject was 3 $m$ in length. Distending pressure was controlled using the valve at the end of the circuit. Pressures were measured at the junction of the circuit and the endotracheal tube $\left(\mathrm{P}_{a o}\right)$, near the tip of the endotracheal tube $\left(\mathrm{P}_{t r}\right)$, and in the alveolar capsule $\left(\mathrm{P}_{a l v}\right)$.

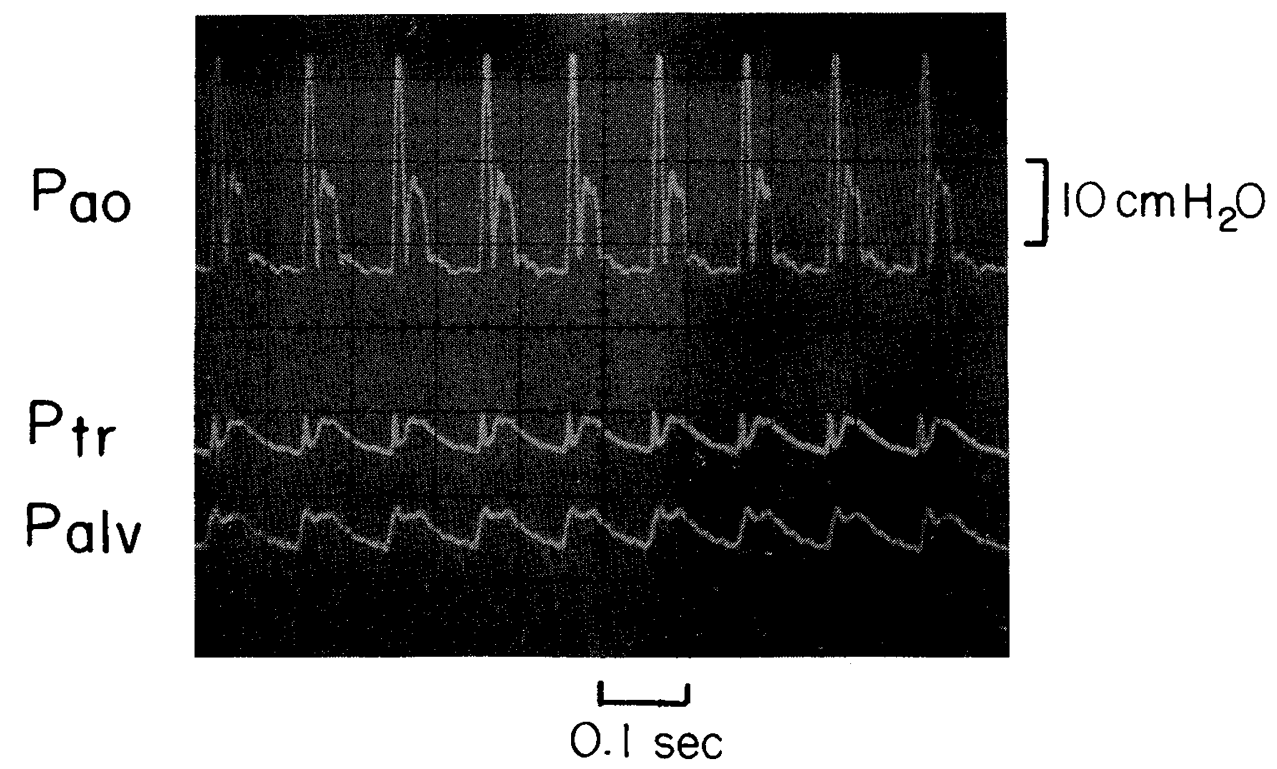

Fig. 3. Tracing of pressures at the airway opening (top), trachea (middle), and alveoli (bottom) versus time for one anesthetized, nonparalyzed animal ventilated at $10 \mathrm{~Hz}$. The gains are the same for all three pressures. 


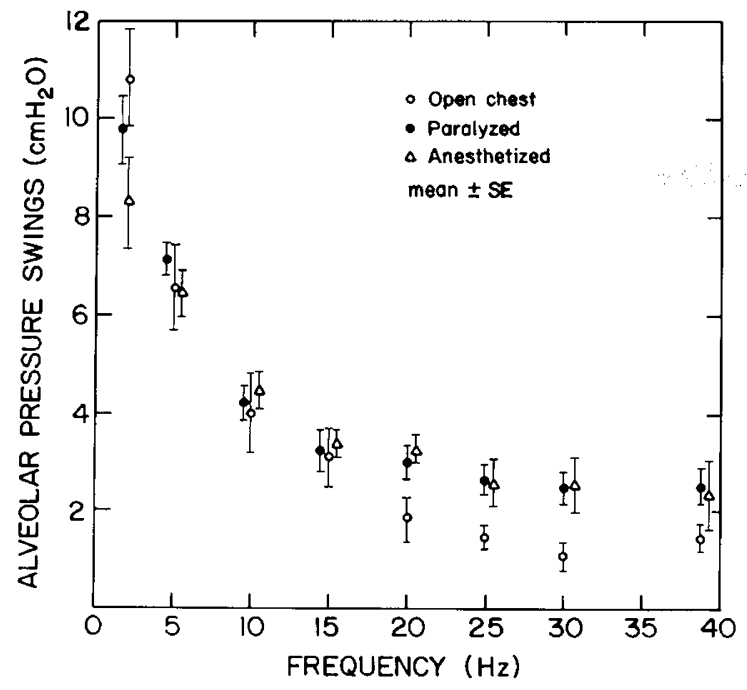

Fig. 7. Alveolar pressure swings $\left(\mathrm{P}_{a l v}\right)$ for the anesthetized (triangles), anesthetized and paralyzed (closed circles), and open chest (open circles) animals plotted versus frequency. Values are mean $\pm \mathrm{SE}$.

namic alveolar pressure fell with increasing frequency. The major drop in pressure swings was in the endotracheal tube with less in peripheral airways. Removal of the rib cage decreased alveolar pressures swings, but muscle paralysis had no effect. Mean pressure was frequency independent and was equal at the airway opening, in the trachea, and in the alveoli.

A major clinical attraction of high frequency ventilation is its potential for providing gas exchange at low dynamic pressures. Work in our laboratory, however, has demonstrated that alveolar pressure swings may exceed those at the airway opening by several fold near the resonant frequency $(1,7)$. Those studies were carried out in such a way as to provide interpretable physiologic data, but not in a manner exactly analogous to clinical high frequency ventilation. The three major differences between the two studies are the waveform of the forced oscillations applied at the airway opening, the magnitude of the pressure and flow swings, and the fact that the original studies were done in the absence of the chest wall. In the excised lung study sinusoidal low flow (less than $0.1 \mathrm{l} / \mathrm{s}$ ) and pressure (less than 0.2 $\mathrm{cm} \mathrm{H}_{2} \mathrm{O}$ ) oscillations were used. This was done to ensure that lung responses (flows and pressures) remained linear. In the present study the pressure waveform was not sinusoidal, and the amplitude of pressure oscillations was much greater $(25-30 \mathrm{~cm}$ $\left.\mathrm{H}_{2} \mathrm{O}\right)$.

One consideration in the interpretation of these data is that although they are discussed in terms of the fundamental frequency, harmonics are present. The major diminution of the peak-to-peak pressure swings is in the higher harmonics, and thus the frequency relationship of alveolar to airway opening pressure may not apply when the airways are oscillated with a sinusoidal wave form.

Using our techniques we were able to partition drops in dynamic pressure between the endotracheal tube and the lung itself. Not surprisingly, the endotracheal tube accounted for the largest drop. This is because flows are highest in the endotracheal tube, thus making resistive losses maximal there, and because the endotracheal tube accounts for much of the total inertance of the system. In terms of clinical application, it is clear that the pressure the alveoli are exposed to is better represented by pressure swings in the trachea than those at the airway opening.

We sought to separate effects of respiratory muscle tone and the rib cage itself by studying the animals with anesthesia alone, following muscle relaxation, and after removal of the rib cage. We noted no differences when results before and after paralysis were compared. This may be because muscle tone has little effect on respiratory system impedance in the rabbit, but may also be a result of the deep anesthesia and lack of muscle tone prior to administration of pancuronium. In most instances the animals were not making spontaneous respiratory movements prior to muscle relaxation. Removal of the rib cage, on the other hand, decreased the alveolar to tracheal dynamic pressure ratios. Removal of the rib cage decreases respiratory system impedance by removing rigid boundary conditions which should decrease alveolar pressure swings. However, it also allows lung volume to increase, which should increase elastance, and increase alveolar pressure swings. Evidently the reduction in respiratory system impedance by removal of boundary conditions was more significant.

Investigators using some techniques for high frequency or jet ventilation have reported lung volume to increase spontaneously as frequency increased $(4,12)$. We found no substantial difference in mean pressures at the airway opening, in the trachea, or in the alveoli and no effect of frequency on the relationship between mean pressures at the three sites. This indicates that with our system gas trapping and increase in functional residual capacity did not occur and suggests that in the above studies expiratory duration was too short given the tidal volume and expiratory time constants involved (4). Simon et al. (14) reported that mean alveolar pressure is higher than that at the airway opening when sampled by measuring relaxation pressure after airway occlusion. We may have missed regional variations in mean pressure by sampling in only one alveolar location, but otherwise are not able to explain the difference between our results and those of Simon et al. (14).

Our studies were done at a distending pressure of approximately $10 \mathrm{~cm} \mathrm{H}_{2} \mathrm{O}$ after peak inflation, or about $80 \%$ of total lung capacity. This level was chosen because we knew from previous work that adequate gas exchange could be obtained there $(5,6)$. Stiffening the system by increasing lung volume would have the effect of increasing alveolar pressure swings, while carrying the studies out at lower lung volume would result in more pressure inhomogeneity. We observed both of these phenomena in studies done with lower amplitude oscillations (1, 7). Both may have implications for use of HFV in diseased lungs. Alveolar pressure may be higher relative to that at the airway opening in conditions of decreased compliance or when a higher mean distending pressure is required for adequate gas exchange. At low lung volume, or with nonuniformity of airway disease, gas trapping may occur and mean alveolar pressure in some lung segments may be observed to be greater than that at the airway opening.

In conclusion, we have demonstrated that during ventilation with the Emerson flow-interrupting, high frequency ventilator alveolar pressure swings are lower than those at the airway opening, mostly due to pressure drop along the endotracheal tube. Alveolar pressure swings and tidal volume fell with increasing frequency. To minimize alveolar pressure swings during high frequency ventilation one might select the highest frequency at which adequate gas exchange can be achieved.

Acknowledgments. The authors thank Dr. Jeffrey J. Fredberg, Dr. Ann R. Stark, and Dr. Thomas Waggener for their critique of the manuscript and Mr. Ed Teach for help in its preparation.

\section{REFERENCES}

1. Allen JL, Keefe DH, Fredberg JJ, Glass GM, Frantz ID 1983 Alveolar pressures and pulmonary impedance during high frequency oscillation in excised rabbit lungs. Pediatr Res 17:370A

2. Bohn DJ, Miyasaka K, Marchak BE, Thompson WK, Froese AB, Bryan AC 1980 Ventilation by high frequency oscillation. J Appl Physiol 48:710-716

3. Butler WJ, Bohn MB, Bryan AC, Froese AB 1980 Ventilation by high frequency oscillation in humans. Anesth Analg 59:577-584

4. Frantz ID, Close RH 1985 Elevated lung volume and alveolar pressure during jet ventilation of rabbits. Am Rev Respir Dis, in press

5. Frantz ID, Stark AR, Davis JM, Davies P, Kitzmiller TJ 1982 High frequency ventilation does not affect pulmonary surfactant, liquid or morphology in normal cats. Am Rev Respir Dis 126:909-913

6. Frantz ID, Werthammer J, Stark AR 1983 High-frequency ventilation in premature infants with lung disease: adequate gas exchange at low tracheal pressure. Pediatrics 71:483-488 
7. Fredberg JJ, Keefe DH, Glass GM, Castile RG, Frantz ID 1984 Alveolar pressure nonhomogeneity during small-amplitude high-frequency oscillation. J Appl Physiol

8. Goldstein D, Slutsky AS, Ingram RH, Westerman P, Venegas J, Drazen J 1981 $\mathrm{CO}_{2}$ elimination by high frequency ventilation (4 to $10 \mathrm{~Hz}$ ) in normal subjects. Am Rev Respir Dis 123:251-255

9. Jackson AC, Vinegar A 1979 A technique for measuring frequency response of pressure, volume and flow transducers. J Appl Physiol 47:462-467

10. Marchak BE, Thompson WK, Duffty P, Miyaki T, Bryan MH, Bryan AC, Froese AB 1981 Treatment of RDS by high frequency oscillatory ventilation: a preliminary report. J Pediatr 99:287-292
11. Mead J 1969 Contribution of compliance of airways to frequency-dependent behavior of lungs. J Appl Physiol 26:670-673

12. Saari AF Rossing TH, Solway J, Drazen JM 1984 Lung inflation during high frequency ventilation. Am Rev Respir Dis 129:333-336

13. SAS Institute 1980 SAS User's Guide: Statistics. SAS Institute, Cary, NC, pp $139-300$

14. Simon B, Weinmann G, Mitzner W 1982 Significance of mean airway pressure during high frequency ventilation (HFV). Physiologist 25:282

15. Slutsky AS, Drazen JM, Ingram RH, Kamm RD, Shapiro AH, Fredberg JJ, Loring SH, Lehr J 1980 Effective pulmonary ventilation with small-volume oscillations at high frequency. Science 209:609-611

\title{
Laser Investigation of Bilirubin-Photobilirubin Photoconversion
}

\author{
RICCARDO PRATESI, GIOVANNI AGATI, FRANCO FUSI, GIUSEPPE SBRANA, \\ MARIA GRAZIA MIGLIORINI, CORRADO VECCHI, AND GIAMPAOLO DONZELLI \\ Istituto di Fisica Superiore, Università, and Istituto di Elettronica Quantistica, CNR, [R.P.], Istituto Interfacoltà \\ di Farmacologia, Università [G.A., F.F.], Centro di Studio dei Composti Eterociclici, CNR [G.S.], Istituto di \\ Chimica-Fisica, Università [M.G.M.], Istituto di Pediatria, Università [G.D.], Firenze, Italy
}

\begin{abstract}
The reversibility of the configurational photoisomerization process of bilirubin (BR) with laser lines in the blue-green spectral region is investigated. Photoisomerization efficiency of $B R$ is found to depend strongly on wavelength, and to decrease when the excitation wavelength is increased from blue to green. Reversion of $\mathbf{B R}$ photoisomers ( $\equiv$ photobilirubin, PBR) back to native BR is demonstrated for several laser lines by irradiating PBR/ BR mixtures with wavelengths greater than the excitation wavelengths. Green lines turn out to be very efficient for PBR $\rightarrow$ BR reversion. The PBR concentrations at photoequilibrium, obtained from the spectrophotometric data, are in close agreement with the corresponding values measured with the high performance liquid chromatography technique in the case of $10 \mathrm{~nm}$ bandwidth filtered light reported in the literature. The $457 \mathrm{~nm}$ blue laser line produces $32 \%$ PBR concentration at photoequilibrium; only 14, 7 , and 3\% PBR concentrations are produced by the blue-green lines at $488,501,514 \mathrm{~nm}$, respectively. The effect on the photostationary PBR/BR mixture of successive irradiations with different wavelengths, and the influence of the wavelength sequence are reported. In the case of blue lines our results support the assumption of the first-order kinetics for the BR $\rightleftarrows$ PBR photoreaction. Departures are observed with green-lines $(501,514 \mathrm{~nm})$. The present results, together with the i) good clinical efficiency reported for fluorescent green lamps; and ii) slow elimination of configurational photoisomers in infants, tend to confirm the lumirubin-pathway as the main mechanism for phototherapy, and call for clinical investigation of narrow-spec-
\end{abstract}

Received October 26, 1983; accepted September 25, 1984.

Address correspondence R. Pratesi, Istituto di Elettronica Quantistica, CNR, via Panciatichi 56/30, 50127 Firenze, Italia.

This work has been supported in part by the CNR Special projects "Laser" and “Medicina Preventiva e Riabilititiva." Research Contract CNR 83.02872.56 "Fototerapia dell'iperbilirubinemia." trum lamps with peak emission wavelength in the (biologically safer) $480 \div 530 \mathrm{~nm}$ range. (Pediatr Res 19: 166171, 1985)

Abbreviations
BR, bilirubin
HBR, hyperbilirubinemia
PBRs, photobilirubin
LR, lumirubin
PE, photoequilibrium
HSA, human serum albumin
DAS, difference absorption spectra

The investigation of the photophysical and photochemical properties of BR is of great relevance with a view to the application of phototherapeutical techniques to the treatment of HBR of infants (18). Light-induced conversion of $\mathrm{BR}$ into a mixture of conformational and structural isomers less lipophilic than BR is considered today the main mechanism responsible for the lowering of BR concentration in skin tissues and blood (11). The conformational photoisomers, called collectively PBRs, are known to be unstable geometric configurations of $B R$, which may revert into $\mathrm{BR}$ or go into more stable isomeric forms upon thermal or optical excitation (12). A new structural, nonreversible, isomer of $\mathrm{BR}$ has been recently discovered, and called LR (11). In the following scheme the "fast" anaerobic photochemistry of BR as presently accepted is illustrated (11):

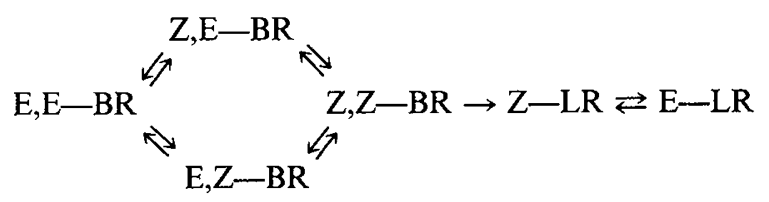

